\title{
A CONSTRUÇÃO HISTÓRICA DA CIDADANIA OCIDENTAL: UMA ABORDAGEM DE GÊNERO
}

THE HISTORICAL CONSTRUCTION OF WESTERN CITIZENSHIP: A GENDER APPROACH

Adriene Neves de Almeida1
https://orcid.org/0000-0002-3115-5799
http://lattes.cnpq.br/9788060194607489

David Junior de Souza Silva²

http://lattes.cnpq.br/4265076306351873

http://orcid.org/0000-0003-2336-4870

Recebido em 20 de janeiro de 2020.

Aprovado em 4 de maio de 2020.

RESUMO: O presente artigo trata sobre o estatuto das mulheres no conceito de cidadania ocidental amplamente utilizado nos Estados contemporâneos, inclusive no Brasil. Malgrado o conceito de pessoa portadora de direitos e o conceito jurídico de cidadão, ambas criações europeias, tenha se difundido no mundo todo conforme a hegemonia do eurocentrismo, diferentes formações sociais realizam o conceito de formas específicas atribuindo estatuto específico às mulheres em cada formação sociocultural. A metodologia consiste de uma hermenêutica histórica da formação do conceito, realçando o estatuto da mulher por ele atribuído. A interpretação debruça-se sobre os autores clássicos do tema, como T.H. Marshall (1967) que caracteriza cidadania através de três elementos: civil, político e social; na construção a partir da política internacional de elementos constitutivos da cidadania contemporânea, analisada por Lafer (2017); e Carvalho (2010) que historiciza a construção do conceito de cidadania no Brasil. Identificamos nos dois casos, tanto no inglês quanto no brasileiro, que às mulheres não foi estendido plenamente o atributo da cidadania. Destarte, em resposta, as mulheres mobilizaram-se para acessar o status atribuído pelo conceito. Sua mobilização foi historicizada aqui: no primeiro momento teve o caráter de garantir que fossem reconhecidas como cidadãs; no segundo, para instituir legislações específicas; no terceiro, para fazer cumprir e ampliar estes direitos.

Palavras-chave: direitos; eurocentrismo; patriarcado; política internacional.

\begin{abstract}
This article deals with the status of women in the concept of Western citizenship widely used in contemporary States, including Brazil. Despite the concept of a person with rights and the legal concept of citizen, both European creations, has spread throughout the world according to the hegemony of Eurocentrism, different social formations carry out the concept in specific ways - assigning specific status to women in each socio-cultural formation. The methodology consists of a historical hermeneutics of the formation of the concept, highlighting the status of the woman assigned by it. The interpretation focuses on the classic authors of the theme, such as T.H. Marshall (1967) that
\end{abstract}

\footnotetext{
${ }^{1}$ Mestranda em Ciência Política pelo Programa de Pós-Graduação em Ciência Política (PPGCP) da Universidade de Brasília (UnB). Bacharela em Ciências Sociais - UNIFAP. E-mail: nevesalmeida3@gmail.com

2 Professor da Universidade Federal do Amapá. Pós-Doutorando pelo Programa de Pós-Graduação em História da Universidade Federal do Amapá - PPGH/UNIFAP. E-mail: davi rosendo@live.com
} 
characterizes citizenship through three elements: civil, political and social; in the construction based on the international policy of elements that constitute contemporary citizenship, analyzed by Lafer (2017); and Carvalho (2010) that historicizes the construction of the concept of citizenship in Brazil. We have identified in both cases, both in English and in Brazil, that the attribute of citizenship has not been fully extended to women. Thus, in response, women mobilized to access the status assigned by the concept. Their mobilization was historicized here: at first it had the character of ensuring that they were recognized as citizens; in the second, to institute specific legislation; in the third, to enforce and extend these rights.

Keywords: rights; eurocentrism; patriarchy; international politics.

\section{INTRODUÇÃO}

No ocidente europeu, as mulheres passaram muito tempo à margem das possibilidades de realização como ser humano. Longo foi o caminho até que as primeiras mulheres pudessem frequentar as escolas, pudessem exercer profissões e realizar-se artisticamente, e pudessem atuar politicamente e serem reconhecidas como sujeitos de direitos em paridade com os homens.

Este artigo tem como objetivo interpretar como se deu a trajetória das mulheres rumo à luta pelo reconhecimento como sujeito humano e social pleno, ou seja, como se deu a construção da cidadania das mulheres no ocidente moderno. Para tanto, o texto investiga como foi construída a noção de cidadania da sociedade moderna ocidental e qual o estatuto da mulher neste conceito de cidadania.

Para interpretação da construção da cidadania no ocidente tomaremos como base o autor alçado a cânone para isto, T.H. Marshall (1967). O autor a caracteriza através de três elementos: civil, político e social. Um momento de nova estruturação da cidadania é o da construção a partir da política internacional da noção de direitos humanos, que foram institucionalizados como elementos constitutivos da cidadania contemporânea, analisada por Lafer (2017). No Brasil, a interpretação canônica é a de José Murilo de Carvalho (2010) que afirma que na construção da cidadania brasileira há uma inversão da ordem histórica dos elementos que a constituem - em relação ao caso inglês.

\section{A INTERPRETAÇÃO DE T. H. MARSHALL}

No capítulo III do livro Cidadania, Classe Social e Status (1967), o sociólogo estadunidense Thomas H. Marshall nos apresenta como a cidadania se constituiu na Europa a partir do século XVIII dividindo-a em três partes (ou elementos): o civil, o político e o social. Utilizando estes elementos, o autor desenvolve uma análise através da história inglesa e trabalha a cidadania a partir de uma construção de valor nacional (MARSHALL, 1967, p. 64), para nos mostrar como está sendo alterado o padrão de desigualdade social.

O primeiro elemento, o civil, "é composto dos direitos necessários à liberdade individual liberdade de ir e vir, liberdade de imprensa, pensamento e fé, o direito à propriedade e de concluir contratos válidos e o direito à justiça." (ibidem, p. 63). O direito civil estava vinculado à "jurisdição dos vários tribunais, dos privilégios da profissão de advogado e, acima de tudo, da responsabilidade de arcar com as custas do litígio" (ibid., p. 65-6). Este elemento componente da cidadania inicia sua constituição a partir do século XVIII e compreende a adição 
gradativa de novos direitos a um status existente (ibid., p. 68).

O segundo componente, o "elemento político deve-se entender o direito a participar no exercício do poder político, como um membro investido da autoridade política ou como um eleitor dos membros de tal organismo. Instituições correspondentes são o parlamento e conselhos de Governo local." (ibid., p. 63). Este direito é estabelecido a partir do século XIX, mas não como um direito novo e sim como acréscimo a outros setores da população; visto que ele não atendia aos preceitos de um estado democrático, o autor os considerava deficientes "não em conteúdo, mas na distribuição" (ibid., p. 69) e também como monopólio de determinados grupos, mas caminhava para uma ideia aceitável pelo capitalismo daquele século. No século XIX a cidadania com os direitos civis era universal, já os direitos políticos não eram considerados parte da cidadania pelo fato de poucas pessoas os possuírem; só em 1918 os direitos políticos passam a ser universais, o que não significa completa igualdade política em termos de cidadania.

Como terceiro elemento temos o social, que refere-se, segundo o autor:

[...] a tudo que vai desde o direito a um mínimo de bem-estar econômico e segurança ao direito de participar, por completo, na herança social e levar a vida de um ser civilizado de acordo com os padrões que prevalecem nas sociedades. As instituições mais intimamente ligadas com ele são o sistema educacional e os serviços sociais (ibid., 63-4).

Este elemento segundo o autor vem entrelaçado aos direitos políticos. Sua constituição se dará através da participação nas comunidades locais e associações funcionais (ibid., p.70), que na Inglaterra passou a ser dado através da Poor Law (Lei dos Pobres) que servia para uma diminuição da pobreza e da vadiagem, fazia com que a renda se ajustasse às necessidades sociais e o status do cidadão, para que esse tivesse um mínimo de poder de compra, isto era considerado a primeira fase da Lei. Na segunda fase a Lei se preocupava apenas com aqueles que não podiam trabalhar por causa de idade ou doença e com as pessoas que recorriam solicitando ajuda. Quem era atendido pela Lei se tornava um não cidadão devido ao fato de o status de cidadão ser desligado da garantia dos direitos sociais básicos oferecidos pelo Estado, tendo também a educação como forma de direito, era colocado que o Estado devia oferecer às crianças uma educação para poder compreender seus direitos e deveres como cidadão, considerado como "primeiro passo decisivo em prol do restabelecimento dos direitos sociais da cidadania no século XX" (ibid., p.74).

No século XX o direito social se torna forte e funciona como um fator crucial para a redução das desigualdades, o que importa aqui é que a vida civilizada tenha menos risco e insegurança. Pretende-se ter uma igualdade entre os menos favorecidos e os mais favorecidos, a igualdade de status é mais importante que a de renda (ibid., p.95). É dado de acordo com o autor o direito à igualdade de oportunidade, com objetivo de eliminar o privilégio hereditário (ibid., p.101); essa igualdade é oferecida quando as crianças têm acesso à educação.

No texto, Marshall nos mostra como a cidadania é uma forte aliada para a diminuição da desigualdade social visto que ela traz à tona preceitos de universalidade e igualdade entre os cidadãos. A educação passa a ser fator primordial para a liberdade civil e o exercício da cidadania, era essencial ao cidadão saber ler e escrever para ter acesso aos direitos. Esta educação passa por um processo de estratificação social, que nos faz perceber que nem todos teriam acesso fácil à cidadania devido à falta de conhecimento, de modo que o Estado deveria prover o acesso à Educação infantil para que quando adultos compreendessem os seus direitos. 
O autor é claro em nos dizer que a educação nos faz desiguais, devido ao fato de existir uma separação em três grupos que testariam o conhecimento de cada um. Recorre-se a Bourdieu (1992) para aprofundar esta questão e entender que essa desigualdade pode vir de fatores como o que ele chama de "capitais" que são recursos ou poderes que se dividem em quatro, chamados de capital cultural: saber e conhecimento adquirido; capital social: relações sociais revertidas em capital; capital econômico: renda e salário e; capital simbólico: prestígio e honra. Para ele as pessoas têm que ser compreendidas a partir de onde vem e o que adquiriram ao decorrer da vida, como exemplo, não podemos afirmar que uma pessoa que já foi à França e outra que só a conhece pela TV tenham as mesmas experiências do lugar, então é necessário que compreendamos muito bem para que a educação não seja excludente.

Utiliza-se Bourdieu (1992) para discutir com Marshall (1967) o quanto o argumento apresentado caminha para uma discussão importante do fator educacional para a construção dos cidadãos. No momento em que Marshall apresenta a importância da educação não se pode deixar de lado o quão excludente a educação pode se tornar. Assim é possível afirmar que a educação não é 'completa' e igual para todos. Deste modo uns terão mais acesso que outros e a ideia de igualdade para todos perde a força, pois de acordo com Marshall a educação é primordial para o acesso a cidadania e a possibilidade de se tornar um cidadão. $\mathrm{Na}$ sociedade capitalista o indivíduo tem que ter a possibilidade do acesso, não se preza em dar condições iguais para todos, quem conseguir 'se esforçou o suficiente e quem não conseguiu devia ter se esforçado mais'. Assim, Bourdieu traz a noção de capitais para explanar o porquê do fracasso de uns, vai além de ter oportunidade é necessário capitanear diversos conhecimentos.

Marshall traz à tona o termo status que remete aos direitos que se possui (cidadania). Na Idade Média esse status "era a marca distintiva de classe e a medida de desigualdade" (ibid., p.64). Mais adiante na história esse status é dado a todos que fazem parte de uma sociedade e parte do pressuposto de igualdade de direitos e obrigações, apesar de não existir um princípio universal de como eles serão, as sociedades acabam criando um modelo ideal de cidadania em que prevaleça a igualdade, nesta discussão aparece a problemática da classe social que acaba tornando os homens desiguais.

A desigualdade social no capitalismo existe como forma de fortalecer o incentivo ao esforço. Deste modo a manutenção da desigualdade fortalece o capitalismo, na medida em que este é constituído pelos que têm capital e aqueles que precisam vender sua força para adquirirem renda para sobreviver. Para que cidadania e capitalismo coexistam é necessário que exista o menor grau de desigualdade na sociedade.

Para Marshall, a cidadania torna alguns tipos de desigualdades inaceitáveis devido ao fato do engrandecimento do status de cidadania, nem todos serão iguais pelo motivo de não estar se buscando uma igualdade absoluta, mas sim aquela que seja mais aceita para conviver com esse novo status de cidadania. Começa-se então a se discutir um tipo de justiça social que visa a "remover desigualdades que não podem ser consideradas como legítimas" (ibid., p. 109). As oportunidades devem estar postas a todos de modo igualitário, mas para que todos a alcancem isso irá depender do esforço que cada um fará para conseguir. Marshall afirma que "distinções de classe podem sobreviver que não possuam nenhuma função econômica apropriada, e diferenças econômicas que não correspondam a distinções de classe aceitas." (ibid., p. 109).

Deste modo as pessoas não estão tão preocupadas em ter um salário que traga vantagens substanciais, o salário alto nos diz o autor é apenas simbólico visto que operam como status industriais e não uma genuína estratificação econômica (ibid., p. 112), porque as pessoas já 
possuem os serviços essenciais oferecidos pelo Estado e compreendem que o Estado deve ofertar esses serviços a todos, então esse sistema de desigualdade econômica é considerado aceito, pois não deve ocorrer uma busca incessante por uma melhora nas condições, todos tem aquilo que conseguiram possuir.

A desigualdade econômica permitida nesta sociedade fere sem medida as mulheres, pois estas não são reconhecidas como sujeitos e não têm acesso aos meios para exercer a sua existência enquanto cidadãs visto que a elas foi negado os mesmos acessos que aos homens. A educação aparece mais uma vez como estratificadora em virtude da impossibilidade das mulheres nesse período terem acesso à escola. A elas eram relegados os trabalhos domésticos, e não podemos esquecer das mulheres negras que sequer eram mencionadas, estas viviam na escravidão e não possuíam nada e as mulheres é legado os trabalhos menos prestigiados que possuíam carga horária altíssima.

Assim, mesmo que este status de igualdade reconheça as mulheres como indivíduos e conceda os direitos já oferecidos aos homens, a desigualdade de gênero não será solucionada apenas com o reconhecimento do status de igualdade, pois a raiz do problema é social e necessita de uma mudança no cerne da sociedade.

Isto posto, a desigualdade não pode ser aceita de nenhuma maneira e em nenhum nível da vida humana, a construção de uma igualdade entre os indivíduos acontece quando a sociedade reconhece a existência de todos os indivíduos e os torna parte da concessão de direitos. A ideia que se tem de cidadania só poderá ser afirmada universal e igual quando todos tiverem acesso ao reconhecimento por parte do Estado.

Apresenta-se então a necessidade de que a sociedade tenha uma melhor distribuição de renda, que os serviços estatais sejam ofertados com eficiência e qualidade a todos que precisarem. Para que as mulheres, os negros e os LGBT's possam ser reconhecidos enquanto cidadãos é preciso dar condições para sua existência. Afirmar que todos têm oportunidade é invisibilizar as demais questões que atravessam a sociedade, as dificuldades que cada um possui para poder existir.

Analisar estas particularidades hoje em dia é de suma importância para a construção de direitos. Reconhecer que os pontos de partidas não são os mesmos, olhar historicamente e compreender a urgência em englobar estas questões. As mulheres tiveram que lutar muito para isso, o que não foi diferente dos negros e LGBT's. Estes segmentos da sociedade não fizeram parte deste escopo de cidadania a qual Marshall nos mostra, o ponto de partida da cidadania negou a existência deles.

Este conceito de cidadania é construído para as necessidades e possibilidades de usufruto da masculinidade, da branquitude e do capital. Aqueles não incluídos nestes recortes sociais ficam alienados da cidadania. A construção do conceito europeu de cidadania é a construção do conceito eurocêntrico de minorias sociais - as constitui historicamente na medida em que as exclui do conceito jurídico recém-criado de cidadania. Os direitos, sociais, civis e políticos, dos homens europeus são criados pela desconsideração e apagamento dos direitos femininos e dos direitos étnicos - dos povos ameríndios e africanos, dragados também para a ocidentalidade pela colonização e escravização europeia.

\section{A EMERGÊNCIA DA POLÍTICA INTERNACIONAL E O CONCEITO OCI- DENTAL DE CIDADANIA}


$\mathrm{Na}$ história da construção do conceito ocidental de cidadania, após a progressiva constituição histórica dos direitos políticos, sociais e civis relatada por Marshall, identifica-se um outro momento histórico no qual a emergência de uma política internacional aparece como fator constituinte de elementos estruturantes deste conceito de cidadania.

Esta política internacional institucionalizou a noção de direitos como elemento fundamental da noção de pessoa do ocidente contemporâneo e, por meio de acordos interestatais, institucionalizou esta noção nos arcabouços legislativos internos dos Estados-Nação.

Para a compreensão do significado contemporâneo da noção de cidadania é importante este momento em que ela é construída a partir de dinâmicas ocorridas nesta, inédita na história do ocidente, dimensão internacional. Assim, é preciso levar-se em conta o reconhecimento da condição humana como perspectiva para os direitos humanos. Para o conceito ocidental de cidadania é fundamental a noção de direitos humanos. Para refletir sobre isso, Comparato (2013) nos diz que é na era axial ${ }^{3}$, quando o homem tem consciência de si mesmo, o marco para a construção de um ideal de direitos humanos:

Em suma, é a partir do período axial que, pela primeira vez na História, o ser humano passa a ser considerado, em sua igualdade essencial, como ser dotado de liberdade e razão não obstante as múltiplas diferenças de sexo, raça, religião ou costumes sociais. Lançaram-se assim os fundamentos intelectuais para a compreensão da pessoa humana e para afirmação de direitos universais, porque a ela inerentes (COMPARATO, 2013, p.24).

Desta forma, podemos falar da reflexão dos direitos humanos como promotores de cidadania. Apesar deste reconhecimento demorou-se muito para que de fato os diplomas legais ${ }^{4}$ reconhecessem que todos os seres humanos são iguais.

O consenso sobre a igualdade de toda a humanidade se estabelece efetivamente apenas com a afirmação do Estado Liberal e começa a ser discutido para a garantia de direitos, já que o status de cidadão é dado para assegurar um rol mínimo de direitos (SALES, 2012). Como marco histórico temos a Revolução Francesa e a Declaração dos Direitos do Homem e do Cidadão em 1789, que consagram formalmente, pela primeira vez na história do ocidente, os direitos individuais e cidadania entendida como direitos políticos.

Com esses entendimentos e posterior afirmação do Estado Democrático de Direito temos, como aponta Sales:

[...] marcos fundamentais a Constituição Mexicana de 1917 que traziam seu bojo uma série de regulamentações visando uma sociedade mais igualitária servindo de base para a posterior Constituição Alemã de 1919, conhecida como Constituição de Weimar também reconhecida como um marco na defesa da cidadania. Através desses documentos, o cidadão passa a ser entendido como aquele que está sob a soberania de um Estado e recebe deste a garantia dos direitos civis, políticos, econômicos, sociais e culturais e consequentemente passam a ter deveres. Assim, cidadão é o sujeito de direitos e deveres que está submetido à soberania de um Estado. (2012, p. 12-13).

\footnotetext{
${ }^{3}$ Conceito cunhado por Karl Jaspers representa o período de 200 a 800 a.C. De acordo com Libiano (2002) é o "ponto de nascimento espiritual do homem, onde se realizou de maneira convincente, tanto para o Ocidente como para a Ásia e para toda humanidade em geral, para além dos diversos credos particulares, o mais rico desabrochar do ser humano; [...] ter-se-ia encontrado para todos os povos um quadro comum, permitindo a cada um melhor compreender sua realidade histórica. [...] É então que surgiu o homem com o qual convivemos ainda hoje” (p.163).

${ }^{4}$ Diplomas legais: instrumento formal que compreende articuladamente várias disposições jurídicas.
} 
Neste momento, a cidadania é compreendida associada à submissão dos sujeitos a um Estado soberano - e seu exercício está restrito portanto aos limites da soberania deste Estado.

Todavia, os desenvolvimentos históricos da primeira metade do século XXI impuseram a necessidade de uma controle interestatal da forma como cada Estado garante a efetivação das cidadania para seus cidadãos. Os direitos humanos são deste modo internacionalmente institucionalizados, pois os ideais que estavam em vigor eram insuficientes, como afirma Sales:

[...] frente aos acontecimentos que a Europa e o mundo vivenciaram durante a Segunda Guerra Mundial (1939-1945). As atrocidades cometidas pelo nazismo e a descartabilidade da vida humana neste período impuseram a necessidade de que a proteção da cidadania e dos direitos humanos ultrapassasse as fronteiras do Estado (Idem, p. 13).

Os direitos humanos trazem na sua constituição a cidadania como direito humano universal fundamental. Assim, com Hannah Arendt - conforme nos conta Celso Lafer - o conceito de cidadania passa a ser "o direito a ter direitos", constituída pela perda de nacionalidade já que só os nacionais tinham acesso a direitos. Lafer (1997) nos apresenta o seguinte:

A experiência histórica dos displaced people levou Hannah Arendt a concluir que a cidadania é o direito a ter direitos, pois a igualdade em dignidade e o direito dos seres humanos não é um dado. É um construído da convivência coletiva que requer o acesso a um espaço público comum. Em resumo, é esse acesso ao espaço público - o direito a pertencer a uma comunidade política - que permite a construção de um mundo comum através do processo de asserção dos direitos humanos (LAFER, 1997, p. 58, grifo do autor).

Desta forma, a concepção de cidadania que se constrói no ocidente moderno está internacionalmente vinculada aos direitos humanos, que ganham materialidade formal definitiva com a assinatura e publicação da Declaração Universal dos Direitos Humanos na Assembleia da ONU de 1948, e a partir da qual serão institucionalizados nos Estados-Nação, vindo a compor de forma indissociável o conceito jurídico interno de cidadania destes.

\section{A CONSTRUÇÃO HISTÓRICA DA CIDADANIA NO BRASIL}

No Brasil a discussão acerca da cidadania é estudada a partir da independência do Estado Brasileiro da Coroa Portuguesa. Este fato aponta para as mudanças na garantia de direitos.

Desse modo, José Murilo de Carvalho com o seu livro Cidadania no Brasil: o longo caminho (2010) nos mostra como se deu o processo de construção da cidadania no Brasil, seus preceitos estruturantes e quais as dificuldades enfrentadas para o exercício pleno. Neste sentido, ele apresenta que:

Cidadania plena, que combine liberdade, participação e igualdade para todos, é um ideal desenvolvido no ocidente e talvez inatingível [...] tem servido de parâmetro para o surgimento da qualidade da cidadania em cada país e em cada momento histórico (ibid., p. 09).

Tratando-a como um ideal o autor irá discorrer sobre o que significa cada direito e o que é necessário para que este seja completo. 
Direitos civis são direitos fundamentais à vida, à liberdade, à propriedade perante lei [...] são direitos cuja garantia se baseia a existência de uma justiça independente, eficiente, barata e acessível a todos. É possível haver direitos civis sem direitos políticos. Estes se referem à participação do cidadão no governo da sociedade. Seu exercício é limitado a parcela da população e consiste na capacidade de fazer demonstrações políticas, de organizar partidos, de votar, vontade de ser votado. [...] quando se fala de direitos políticos, é do direito do voto que está se falando. [...] Não pode haver direitos políticos sem os direitos civis. Pois, assim a liberdade de opinião e organização não serão contemplados o exercício do voto só formalmente sendo considerados manobras para justificar governos do que como representação dos cidadãos. Os direitos sociais garantem a participação na riqueza coletiva. Eles incluem o direito à educação, ao trabalho, ao salário, à saúde, à aposentadoria. A garantia de sua vigência depende da existência de uma eficiente máquina administrativa do Poder Executivo. [...] Os direitos sociais permitem às sociedades politicamente organizadas reduzir os excessos de desigualdade produzidos pelo capitalismo e garantir um mínimo de bem estar para todos. A ideia central em que se baseiam é a de justiça social (2010, p. 09 - 10).

Apresentados os direitos, o fator que é condição seu exercício é a educação, que se além do mais se estabelece como requisito para acesso aos demais direitos, possibilitando o conhecimento dos mesmos para que seja possível a organização e a luta pela sua efetivação. Carvalho aponta que a ausência de educação tem sido sempre um dos principais obstáculos à construção da cidadania civil e política. A visão do autor é de que educação é um meio de transformação social, ter conhecimento é ter poder sobre aquilo que está sendo discutido e poder assim criar estratégias para garantia de direitos. A educação é apresentada como fator preponderante em termos de concepção dos direitos, pois só assim tem-se entendimento sobre os assuntos de nosso interesse. Novamente, há a elisão da dimensão da educação como naturalizadora da desigualdade social bem como reprodutora das relações sociais e da visão de mundo das classes dominantes, ademais avessas à efetivação de direitos às classes dominadas.

$\mathrm{Na}$ pesquisa de Carvalho, o modelo inglês que apresenta os direitos de forma cronológica sendo conquistados pelo povo ao longo dos anos, não se aplica ao Brasil. Primeiro porque é necessário compreender que cada país segue uma história e lógica próprias; segundo porque no Brasil convivemos com grande instabilidade política ao longo de nossa história.

Uma das especificidades cruciais do Brasil é a escravidão como instituto básico da formação econômica e social do país. Segundo Carvalho, "No período colonial o que era deveras negativo para a cidadania foi a escravidão" (ibid., p.19); "Escravidão e grande propriedade não constituíram ambiente favorável à formação de futuros cidadãos” (ibid., p. 21). Existe uma população semi-cidadã livre, mas que não tinha condições para o exercício dos direitos civis sobretudo a educação. A cidadania não era completa neste período, pois não existe igualdade perante a lei e nem o reconhecimento da igualdade entre todos. Não se pode então falar em república, pois para o autor "não havia sociedade política; não havia "repúblicos", isto é, não havia cidadãos" (ibid., p. 23-4).

Assim o primeiro passo para entender a cidadania está no âmbito da constituição da relação da sociedade com o Estado e com a nação, o que implica apontar o reconhecimento nacional e a luta territorial. Construindo, desse modo, o sentimento de povo, portador de uma nacionalidade passível de agregar reconhecimento jurídico de pertencimento. No Brasil, este sentimento foi sendo construído e se firmando de maneira gradual, no momento em que existe a necessidade de defesa do território este sentimento se consolida. 
Elencamos, como aponta Carvalho (2010), um segundo passo: o de que seguindo o modelo inglês a população tome conhecimento de seus direitos civis e possa a partir deles reivindicar a existência de direitos políticos para assim participar do processo democrático representativo e consequentemente adquirir direitos sociais, que garantem a promoção do Estado de BemEstar no qual as desigualdades possam ser ao máximo diminuídas.

Estes passos demoraram a se concretizar no Brasil. Antes dos direitos civis ocorre a regulação dos direitos políticos, tendo ela caráter liberal. No entendimento do autor, por não contemplar a totalidade de seres humanos pertencentes à nação, as mulheres não estavam capacitadas ao exercício do voto e assim como outras demais pessoas que não apresentavam as características necessárias, não podemos falar de aquisição e exercício cívico, ele era meramente formal. As pessoas não estavam exercendo um direito, mas sim o domínio político local (2010, p.33). O voto era tratado como mercadoria, tendo em vista a não observância dos direitos sociais e civis, existia uma forte dependência dos mais pobres para com a elite.

No Brasil, a trajetória de consolidação dos direitos torna os direitos sociais frágeis, pois primeiro obtivemos os direitos sociais e posteriormente o político e o civil. Para Carvalho (2010) o Brasil não teve uma revolução propriamente dita.

Seguindo a linha de raciocínio de Carvalho, Venceslau Souza (2006) conclui que no Brasil as pessoas não conquistaram os direitos, mas estes foram sendo concedidos pelo Estado. Observando a ordem descrita acima, os direitos sociais são dados a partir da "Revolução de 30", sendo este o marco desta concessão com a construção de um governo populista, na qual Getúlio Vargas era considerado "pai do povo". Podemos perceber neste a proposta do autor ao conceito de Estadania, como sendo aquele que é fruto de uma negociação com o governo, sendo mais do Estado do que dos cidadãos. Os sindicatos estão na ponta desta conversa, pois as primeiras "reivindicações" por direitos estão na esfera do trabalho.

Assim, de acordo com Souza (ibid., p.211) "no Brasil não houve um atrelamento dessas três dimensões políticas. O direito a esse ou àquele direito [...] não garantiu o direito a outros direitos". Surge a tese de que a cidadania no Brasil é inconclusa, pois os regimes não efetivaram a existência deste sentimento, a sociedade acabou não tomando para si o domínio sobre esta esfera.

Souza aponta o questionamento de Carvalho "que tipo de cidadania poderia daí resultar? [... sua resposta é de que no mínimo que se pode esperar é por um enaltecimento do Executivo" (ibid., p.212). Isso diminui a autonomia social. Assim "o cidadão em construção ainda não tivera tempo de aprender a ser cidadão, mas a prezar por líderes fortes, geralmente o chefe do executivo" (ibid., 213). Desta forma, a Constituição brasileira teve muitos direitos dados pelo Estado, mas houve também muita luta por parte dos novos sujeitos para que contasse no texto suas pautas.

Destarte, os direitos humanos são incorporados no Brasil a partir da Constituição de 1988, que nomeia os direitos e indica os instrumentos para sua garantia e efetividade (ADORNO, 2008). Vinculada à Declaração Universal de Direitos Humanos (1948), que reconhece que todo indivíduo deva ser protegido de barbaridades que possam ocorrer por parte do seu Estado. Recém-saído de um regime ditatorial e caminhando para a democracia, via-se a necessidade de introduzir a concepção de cidadania a nossa Carta Magna.

Dentro dessa concepção Adorno (2008) nos coloca ainda que para além dos direitos sociais, civis e políticos ocorre uma "multiplicação de direitos especiais" (ibid., p.196). Neste processo o homem passa "não mais a ser como ser genérico (sujeito portador de universalidade 
abstrata), porém histórico e transitório dotado de particularidades e singularidades, do que decorre a reivindicação de múltiplos sujeitos de direito" (ibid., p. 196) entendendo as mulheres também como sujeitos.

Esta "multiplicação de direitos especiais" acontece com "as declarações, pactos e convenções no âmbito da ONU” (ibid., p.196), que trazem à tona a proteção de novos sujeitos. Não se trata mais de um sujeito e esse sujeito ser homem. Passa-se a compreender as diversas concepções de sujeito, sendo estes: as mulheres, os idosos, as crianças, os LGBT's. Estes novos sujeitos constatam a mudança social que ocorre no mundo e a necessidade de identificar e dar voz a eles.

Estes vivem um momento importante na história da consolidação de seus direitos constitucionalmente reconhecidos, pois é nesse contexto que permite a estes que acessem o Estado de modo formal. O impasse passa a ser a garantia dos direitos, Adorno (2008) apresenta em seu texto que ocorre violação dos direitos humanos no Brasil, como em outras partes do Ocidente. Nos informa que há dificuldade dos cidadãos e cidadãs vivenciarem no seu cotidiano todo o avanço da legislação.

$\mathrm{O}$ direito mais fundamental, ou seja, o direito à vida "persiste de modo escandalosamente desigual" (ibid., p.215). Dados recentes apontam que um homicídio contra as mulheres ou feminicídio ${ }^{5}$, ocorram a cada 2 horas no Brasil; em 10 anos houve um aumento significativo no percentual de mulheres negras assassinadas; a cada 28 horas uma pessoa LGBT é assassinada ${ }^{6}$. Estes dados evidenciam a gravidade da problemática. Apontam o quanto a sociedade brasileira é machista, racista e lgbtfóbica e a importância de uma mudança social para que estes possam viver em uma sociedade que os respeite e se torne segura para existirem. Quando considerarmos os dados sobre a saúde pública, segurança pública e educação no Brasil é possível percebermos o quanto os serviços mais básicos ainda faltam para que os cidadãos e as cidadãs usufruam uma cidadania completa.

Assim, para o feminismo os avanços nas legislações tornam-se importantes e uma bandeira de luta para que as declarações e os pactos sejam cumpridos em todos os Estados membros da ONU. Até então a luta era para serem reconhecidas enquanto cidadãs, sendo reconhecidas a luta agora é para o cumprimento e cada vez mais ampliação dos direitos.

\section{CONSIDERAÇÕES FINAIS}

A interpretação de Carvalho tem como problema epistemológico o submeter-se à interpretação científica inglesa sobre o tema, alçada à categoria de interpretação padrão-universal para as interpretações particulares-periféricas. Ao mesmo tempo, tem como problema a elevação da história inglesa como padrão em relação à qual a história brasileira se diferenciaria - e nesta diferenciação estaria a raiz de sua não-realização plena.

A não-realização plena da cidadania no Brasil se dá por outros motivos, muitos dos quais beneficiou-se a Inglaterra: a herança escravocrata, que perpassa a democracia depois de 350 anos de escravidão; a ferida colonial; e o imperialismo contemporâneo, do qual deriva a

\footnotetext{
${ }^{5}$ Dossiê Violência contra as Mulheres. Disponível em: http://www.agenciapatriciagalvao.org.br/dossies/violencia/pesquisa/mapa-da-violencia-2015-homicidio-de-mulheres-no-brasil-flacsoopas-omsonu-mulheresspm-2015 (Acesso em $30 / 04 / 18)$

${ }^{6}$ Relatório 2016 Assassinatos de LGBT no Brasil. Disponível em: https://homofobiamata.files.wordpress.com/2017/01/ relatc3b3rio-2016-ps.pdf (Acesso em 30/04/18)
} 
impossibilidade da realização plena da democracia aqui, uma vez que esta é permanente perturbada pela ação de países imperialistas, que impõem seus interesses aqui em sacrifício da soberania do Brasil e da cidadania dos brasileiros.

Ambos os autores contam a história da cidadania do ponto de vista daqueles critérios que pertencem ao universo masculino. Não há, na tipologia adotada, um tipo que corresponderia aos direitos específicos das mulheres, que poderiam ser concebidos como direitos de gênero ou cidadania feminina: licença-maternidade, direitos reprodutivos, licença menstruação e diretos menstruais, não constam no arcabouço tipológico criado pelos autores - evidenciando na interpretação científica a mesma lacuna do desenvolvimento histórico patriarcal; outrossim, não constam no trabalho teórico dos autores nenhuma categoria que expresse o acesso diferencial que as mulheres têm ao trio de direitos instituídos na Europa: suas limitações ao exercício pleno de direitos civis (limitado pelas ameaças constantes e reais de estupro, pela não regulamentação de direitos reprodutivos, como a interrupção da gravidez), sociais (a não consideração da forma do direto instituído da diferenciação biológica e dos papeis sociais historicamente desempenhados pelas mulheres) e políticos (as barreiras para disputar eleições e clivagens dentro das próprias instituições partidárias).

A visão científica dos autores sobre a cidadania é exclusivamente patriarcal. Ao não tomarem como dado científico a lacuna no que concerne à especificidade feminina na composição dos direitos estruturantes do conceito moderno de cidadania, incorrem na mesma miopia da sociedade que estabeleceu estes direitos em desconsideração à realidade feminina.

Os direitos instituídos no conceito ocidental de cidadania são concebidos como universalmente válidos para todos os seres humanos, porém restringidos àqueles de usufruto do universo masculino - nenhum direito a mais além do que pode vir a ser um direito usufruído pelos homens. A cidadania ocidental se constitui de acordo com as necessidades e interesses das masculinidades hegemônicas. Nisto se realiza a exclusão das mulheres deste conceito.

Também não passa pela interpretação científica masculina canônica da construção ocidental do conceito de cidadania a consideração desigual do exercício pleno dos direitos por pessoas racializadas e etnicamente diferenciadas

A interpretação científica do conceito é espelho de sua constituição jurídica: ambos constituem-se em acordo com a estrutura de poder que prevaleceu conduzindo o campo político e o campo científico na modernidade: o eurocentrismo, o patriarcado e a branquitude. O caráter universal dos direitos atribuídos neste conceito de cidadania unicamente vêm a mascarar a ausência dos direitos específicos necessários para efetivação da igualdade humana das mulheres

\section{RERÊNCIAS}

ADORNO, Sérgio. Direitos Humanos. In: OLIVEN, Ruben George, RIDENTI, Marcelo e BRANDÃO, Gildo Marçal (orgs.). A Constituição de 1988 na vida brasileira. São Paulo: Aderaldo \& Rothschild: Anpocs, 2008.

BOURDIEU, Pierre. A reprodução. Rio de Janeiro: Francisco Alves, 1992.

BRITO, Maria Noemi Castilhos. Gênero e cidadania: referenciais analíticos. In: Revista Estudos Feministas, ano 9, 2001.

CARVALHO, José Murilo de. Cidadania no Brasil: o longo caminho. Rio de Janeiro: Civilização Brasileira, 13 $3^{\mathrm{a}}$ ed., 2010. 
COMPARATO, Fábio Konder. A Afirmação Histórica dos Direitos Humanos. São Paulo: Editora Saraiva, 2010.

ONU. Declaração dos Direitos do Homem e do Cidadão, 1789. Disponível em: $<$ http:/ / www.direitoshumanos.usp.br/index.php/Documentos-anteriores- $\% \mathrm{C} 3 \% \mathrm{~A} 0$-cria $\%$ C3\%A7\%C3\%A3o-da-Sociedade-das-Na\%C3\%A7\%C3\%B5es-at\%C3\%A9-1919/declaraca o-de-direitos-do-homem-e-do-cidadao-1789.html> Acesso em: 28 mar. 2017.

LAFER, Celso. A reconstrução dos Direitos Humanos a contribuição de Hannah Arendt. Estudos Avançados. São Paulo, vol. 11, n. 30, p.55-65, 1997.

LORENZETTO, Bruno Meneses e KOZICKI, Kátia. O conceito de cidadania para Hannah Arendt e Jacques Derrida. In: II Seminário Nacional de Sociologia e Política da UFPR, 2010. Anais do evento. Disponível em: <https://www.academia.edu/4004919/O_conceito_ de_cidadania_para_Hannah_Arendt_e_Jacques_Derrida> Acesso em: 24 jan. 2017.

MARSHALL, T. H. Cidadania e classe social. In: Cidadania, classe social e status. Rio de Janeiro: Zahar Editores, p. 57-114, 1967.

ORGANIZAÇÃO DAS NAÇÕES UNIDAS. Carta das Nações Unidas, 1945. Disponível em: <http://www.oas.org/dil/port/1945\%20Carta $\% 20$ das $\% 20 \mathrm{Na} \% \mathrm{C} 3 \% \mathrm{~A} 7 \% \mathrm{C} 3 \% \mathrm{~B} 5 \mathrm{es} \% 2$ 0Unidas.pdf $>$ Acessado em 28 mar. 17

SALES, Camila Maria Risso. Direitos Humanos das mulheres: cidadania e emancipação. 2012. Trabalho de Conclusão de Curso. (Bacharelado em Direito) Faculdade de Direito de Varginha, Minas Gerais: Varginha, 2012.

SOUZA, Venceslau Alves de. Direitos no Brasil: necessidade de um choque de cidadania. Curitiba: Revista Sociologia Política, p. 211-214, 2006. 